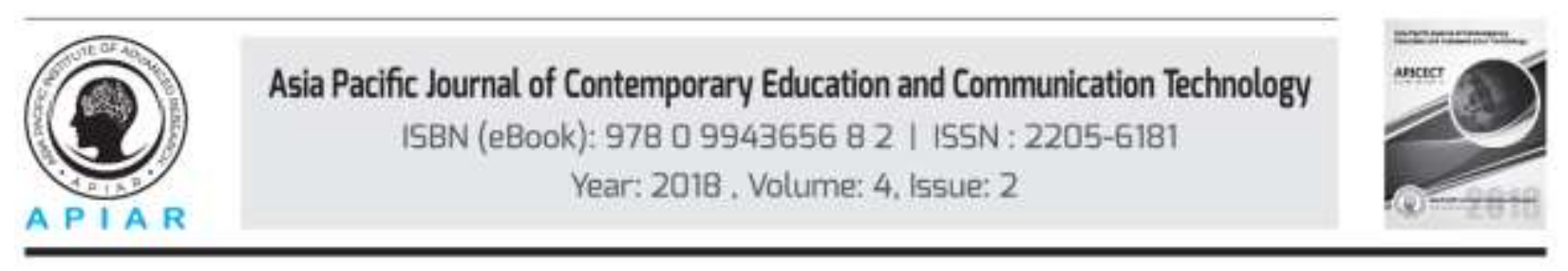

\title{
USING VR TO INCREASE STUDENT ENGAGEMENT AND EMPLOYABILITY SKILLS WHEN TEACHING TAXATION
}

\author{
Terry Filera, Dr Marc Holmes ${ }^{b}$ \\ ab Swansea University, Swansea, UK \\ Corresponding Email: t.filer@swansea.ac.uk
}

\begin{abstract}
Engaging students in the practical uses of taxation through problem-based learning (PBL) can be an effective learning technique to improve student engagement and transferable employability skills. This research extends PBL to provide final year undergraduate students with a "real" client experience through using VR as part of a capital allowances taxation exercise. Students explored their "clients" premises through VR to identify assets that were eligible for their capital allowances claim. Feedback from students was very positive and although most had not used the technology before they thought that it enhanced their learning of the topic and found it fun to use. Furthermore, students requested more use of VR in their studies and thought it helped them to better understand the real applications of UK taxation.
\end{abstract}

Keywords: Employability, Engagement, Taxation, VR

\section{Introduction}

For most taxation educators, the aim in teaching taxation is to use an approach that is effective i.e. students understand the topic being delivered and can apply the knowledge they have learned in a summative assessment successfully. However, there is far more to teaching than helping students to prepare for examinations, one would hope that students enjoy studying the subject, so they may go on to consider it as a future career prospect. To embrace this opportunity students are provided with real life problem-based learning exercises, so they can better understand how taxation works in practice. Educators with previous experience in tax practice and industry can call on previous cases to illustrate the PBL technique being delivered e.g. individual's self-assessment return or completing a VAT return. By taking this approach, students are absorbed in the task of working on the PBL exercise which can make learning more relevant and fun rather than studying tax using a more theoretical approach. Tax is a practical subject and from an early stage of learning, students can perform tax computations for individuals with relatively straight forward circumstances.

From an educational perspective, the aim was to extend the practical aspects of tax further by allowing students to enter a client's premises and identify assets eligible for capital allowances. Previously, taxation students were provided with a "client" scenario which contained a list of assets on a paper exercise that they used to complete their capital allowances claim. By providing a simulation premise through VR students had the opportunity to virtually walk around their client's premises and identify those assets eligible for capital allowances. Not all assets are eligible for capital allowances so accuracy in this identification process is essential to ensure that the capital allowances claim is compliant with HM Revenue and customs rules and guidelines. 


\section{Research Problem}

Is VR a useful tool to assist learning of a taxation topic and as a means to provide employability skills for students studying accounting and taxation in large group.

\section{Literature Review}

For this research the question considered is VR a useful tool to assist learning of a taxation topic and as a means to provide employability skills for students studying accounting and taxation in a large group?

Students learning taxation as part of their undergraduate degree can benefit from a PBL approach as this technique has been applied successfully in various educational disciplines over many years(Boud, 1985; Gijselaers, et al., 1995; Boud \& Feletti, 1997; Anderson \& Krathwohl, 2001). Furthermore, taking this approach can help to develop future professional accountants and tax advisors Markus \& McConnell, (2001), equipping them with the skills they need for future employment Kolb, (1984), Educators who encourage student learning by reference to real world scenarios can help to make the subject more relevant to students. Furthermore, students will learn by doing Kolb, (1984) rather than passive listening in lectures "For the things we have to learn before we can do them we learn by doing them" Aristotle, The Nicomachean Ethics(Ross, et al., 2009).This is particularly relevant for taxation which is a technical and practical subject.

According to Kolb, (1984) there are four types of learners, divergent, assimilating, convergent and accommodating and, to be an effective educator of accounting subjects we need to provide teaching approaches that appeal to all four types to ensure the learner is provided with opportunities to engage with activities using a teaching approach that suits them best. Indeed, Kolb further comments that when learners identify their lesser preferred learning style, they can strengthen their learning using his experiential learning cycle model (Figure 1):
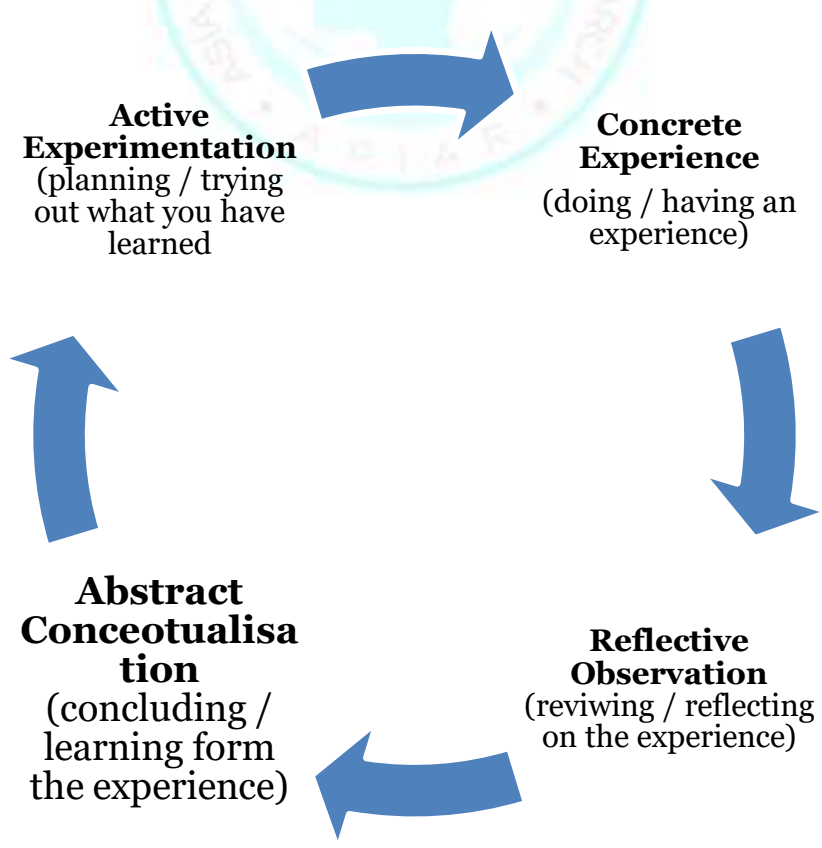

Figure 1: Diagram representing Kolb Learning Cycle 
By introducing VR in the classroom for taxation, students can experience a client and advisor role where VR simulates the real world visit to a client's premises which is not practical for a large group of students to experience in real life(Merchant, et al., 2014).Indeed, the exercise incorporating VR utilizes many learning styles, visual (spatial), aural, verbal, physical, logical, social and solitary that would appeal to most types of learners. There has been a demonstrated benefit from using VR as a teaching tool(Merchant, et al., 2014).

Google cardboard is the VR equipment of choice as it's use of pre-existing mobile phone hardware via a simple and easily constructed holder to make a VR device. This allows for a "Bring Your Own Device" (BYOD) philosophy so that the cost of university owned VR devices can be reduced down to a supporting role for students who do not have suitable devices (Rodriguez, 2016),Google Expeditions is a Google product which allows for VR tours. It has been used to work with school children and demonstrated successfully that it is useful in building collaborative skills amongst the students(Minorcha \& Tudor, 2017). This supports the general research showing that students generally preferred to work in pairs and that learning together facilitates increased performance than in individual learning (Johnson \& Johnson, 2017).

Physical field tours have been shown to encourage active learning(Easton \& Gilburn, 2012), However, they promote a model of privilege and exclusion for students from ethnic minorities or those unable to access the environment(Easton \& Gilburn, 2012). VR technology overcomes this limitation whilst simultaneously allowing for experiential learning and enhancing motivation and engagement through collaboration(Jarmonl, et al., 2009).

While this paper focuses on a classroom intervention, portable VR could also be carried out as mobile learning exercises in a multitude of environments. There is large potential for mobile learning as the students can carry out heutogogical learning (Hase \& Kenyon, 2013)which presents far more opportunities for students to learn and promotes further independence of the learner. Mobile learning has increased in education but has yet to reach it pinnacle so there are areas for further investigation surrounding this topic(Rikala, 2015).

\section{Methodology}

A capital allowances scenario was set up by the educator and various locations within the business premises were captured by photographs well in advance of the student session taking place. Each of the locations in the photographs provided the students with different capital allowances challenges whether the asset was allowed for capital allowances or not and if allowed what type of allowances were eligible. For this scenario, the Monarch Training School was created, a pilot training centre equipped with flight simulators, classrooms, plant rooms, a gym and kitchen canteen. In the scenario, there are twelve virtual rooms for students to explore and evaluate for their capital allowances claim. A large part of the exercise involved putting together an app to allow the student to experience a walk around the premises by using google cardboard headsets with an app downloaded on to their mobile phones before the sessions took place, which would allow students to immerse themselves in the technology.

This preparation took time as proprietary software was tailored to accommodate the twelve virtual rooms of photographs, linking them together so by clicking a button on the google cardboard headset students could move seamlessly from one room to another as if they were there in person. Permissions were needed to install the app on both the Android and Apple stores. Unfortunately, there was a delay in receiving Apple's permission which caused some practical problems on the day but were overcome by having the University's own devices loaded with the app as a backup. 30 google cardboard sets were available having been purchased by the University for educational use. 
Careful planning and preparation for the exercise was vital as this was a large cohort of 200 level 6 students in the first term of their final year studies. To minimize costs the exercise was delivered during students one-hour seminar class that took place on the day after the corresponding lecture. There were six seminar sessions for up to 30 students per session. Students were provided with the usual two-hour lecture on capital allowances that introduced the concept, pro-forma and a worked example. Students were provided with a few questions to practice at home via the University's VLE. Copies of the lecture material had been loaded onto the VLE two days before the lecture.

On the day of the exercise, each seminar class started with the educator giving a brief introduction of how the session would be run providing a copy of the scenario to each student. (AppendixA). Students were asked various questions on their previous use of VR and their perceptions of its application to learning (Appendix B).

Due to delays in obtaining Apple permissions for the app a far greater reliance on the backup android devices was needed plus some students were able to download the app on their Android phones. A small number of students did not own a smart phone, so these students also used the backup devices or the educator's own. See pie graph below for the mix (figure 2).

\section{Type of mobile phone type and suitability for the exercise}

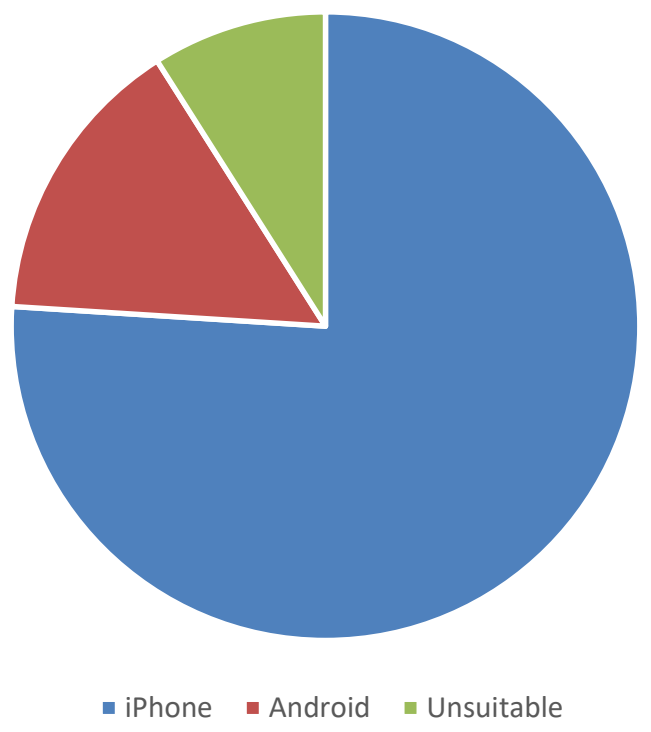

Figure 2: Type of mobile phone type and suitability for the exercise

Students were open minded about the exercise and seemed keen to give it a try with some immediately immersing themselves in the technology which was evident by the way they moved around their space using either chairs on coasters or by standing up and clearing a space in the seminar room to avoid accidents.

Although unintended, larger groups of students shared headsets, with one student exploring the premises and another writing down the assets that they were viewing. By taking this approach, the students were working in a team ensuring that they captured all the information needed to complete the task, which is the approach needed in practice as the client visit would take place on one specific day and all information needed would need to be collated during that visit with follow up phone calls or copy invoices being requested. 
To ensure the exercise made best use of VR, values of each asset in the rooms were included on the photographs for reference and collation purposes. Student comments were that they found this interesting and informative as they had no idea how expensive some assets were (Appendix C).

After students had completed the capital allowances viewing and collation exercise, they were asked to answer a few short questions and their thoughts on using VR for taxation educational purposes (Appendix C).

Students were requested to complete their capital allowances claim before the next lecture in six days' time when the results and feedback would be provided. At the feedback session the educator had a screen capture version of the software that was used to discuss the assets in each room deciding which were eligible for capital allowances and which were not. When the asset list had been completed, students gave their feedback on which items were eligible for ECA, AIA and then WDA's to maximize the client's capital allowances claim. This feedback session concluded the capital allowances exercise.

\section{Conclusion}

Based on student feedback provided on the day of the VR capital allowances exercise, the technology has been useful to assist learning of a taxation topic as many of the students' comments support its further use (appendix c). For the second part of the research question will VR be useful as a means to provide employability skills for students studying accounting and taxation in a large group, again the majority of student feedback was positive as students were seeing tax in practice rather than as a mathematical exercise.

Furthermore, students appreciated the opportunity to experience VR as a unique learning method and to see how capital allowances work in practice. Many students commented that it was fun and they would like to use it more in their accounting studies.

Benefits for the educator is seeing students immersed in taxation smiling and enjoying the experience while providing them with the opportunity to see the subject in its practical application. The educator's intention is to further provide students with relevant examples they could use on their cv's or in an interview answer. Hopefully, future employers would be attracted to shortlist the student for interview due to the additional "real world" skills the student had gained during their undergraduate degree. 


\section{References}

i. Anderson, L. \& Krathwohl, D., 2001. A taxonomy for learning, teaching, and assessing: A revision of Bloom's taxonomy of educational objectives. New York: Longman.

ii. Boud, D., 1985. Problem Based Learning in Education for the Professions. In: D. Boud, ed. Sydney: HERDSA.

iii. Boud, D. \& Feletti, G., 1997. The Challenge of Problem-Based Learning. 2nd ed. London: Kogan Page.

iv. Easton, E. \& Gilburn, A., 2012. The Field Course Effect: Gains in Cognitive Learning in Undergradtuate Biology Students following a Field Course. Journal of Biological Education, 46(1), pp. 29-35.

v. Gijselaers, W. et al., 1995. Education Innovation in Economics and Business Administration: The Case of Problem-based Learning. Norwell, Mass: Kluwer.

vi. Hase, S. \& Kenyon, C., 2013. Self-determined learning: Heutagogy in action. London: Bloomsbury Academic..

vii. Jarmonl, L., Traphgan, T., Mayrath, M. \& Trivedi, A., 2009. Virtual world teaching, experiential learning, and assessment: An interdisciplinary communication course in Second Life. Computers and Education, Volume 53, pp. 169-182.

viii. Johnson, D. \& Johnson, R., 2017. The use of cooperative procedures in teacher education and professional development. Journal of Education for Teaching: International Research and Pedagogy, 43(3), pp. 284-89.

ix. Kolb, D., 1984. Experiential learning: Experience as the source of learning and development. 1st ed. Englewood Cliffs, NJ: Prentice-Hall.

x. Markus, M. \& McConnell, J. P., 2001. Problem-based learning: A pedagogy for using case material in Accounting Education. Accounting Education, 10(1), pp. 61-82.

xi. Merchant, Z. et al., 2014. Effectiveness of Virtual reality-based instruction of students' learning outcomes in K-12 and higher education: A metaanalysis. Computers and Education, Volume 70, pp. 29-40.

xii. Minorcha, S. \& Tudor, A., 2017. Virtual Reality in Eduction. In: Learning Design and Technology Enhanced Learning Special Interest Group, 2oth September. s.l.:The Open University.

xiii. Moon, J., 2004. Handbook of Reflective and Experiential Learning: Theory and Practice. s.l.:USA RoutledgeFalmer.

xiv. Morgan, G., 1997. Communication skills required by accounting graduates: practitioner and academic perceptions. Accounting Education, 6(2).

xv. Rikala, J., 2015. Designing a mobile learning framework for a formal educational context, s.l.: Jyväskylä Studies in computing 220.

xvi. Rodriguez, N., 2016. Teaching Virtual Reality with Affordable Technologies, Lecture Notes on Computer sciences. s.l.:s.n.

xvii. W.D.Ross, Aristotle \& L.Brown, 2009. The Nicomachean ethics. Oxford: Oxford University Press. 


\section{APPENDIXES \\ Appendix A}

Capital Allowances Seminar using VR technology - week commencing $6^{\text {th }}$ November 2017

1. Prior to the seminar taking place download the VR app called ...............................on to your mobile phone from the following locations:

a. Android - Play Store

b. Apple - App Store

2. When you have the VR app you are ready for the seminar session

3. Answer pre-session questionnaire via clicker (TF to circulate clickers)

4. Instructions for this session:

a. You are a tax advisor to the Monarch Training School owned by Thomas Owen and have an appointment to visit the premises to consider a capital allowances claim today.

b. Thomas Owen greets you and gives you a tour of the premises.

c. Open the app downloaded onto your phone and slot your phone in the VR headset provided.

d. Tour the premises room by room identifying as many assets as possible - write these down and compare with your colleagues (fellow students on the same table)

e. Compare your team list with the asset list provided by your manager (TF to provide) and complete your capital allowances claim.

f. Submit capital allowances claim to your manager (TF)

g. Answer post session clicker questions and complete paper questionnaire to record free text on the VR experience.

h. Collect headsets/phones/clickers distributed

i. Manager (TF) to provide feedback on student capital allowances claim 


\section{Appendix B}

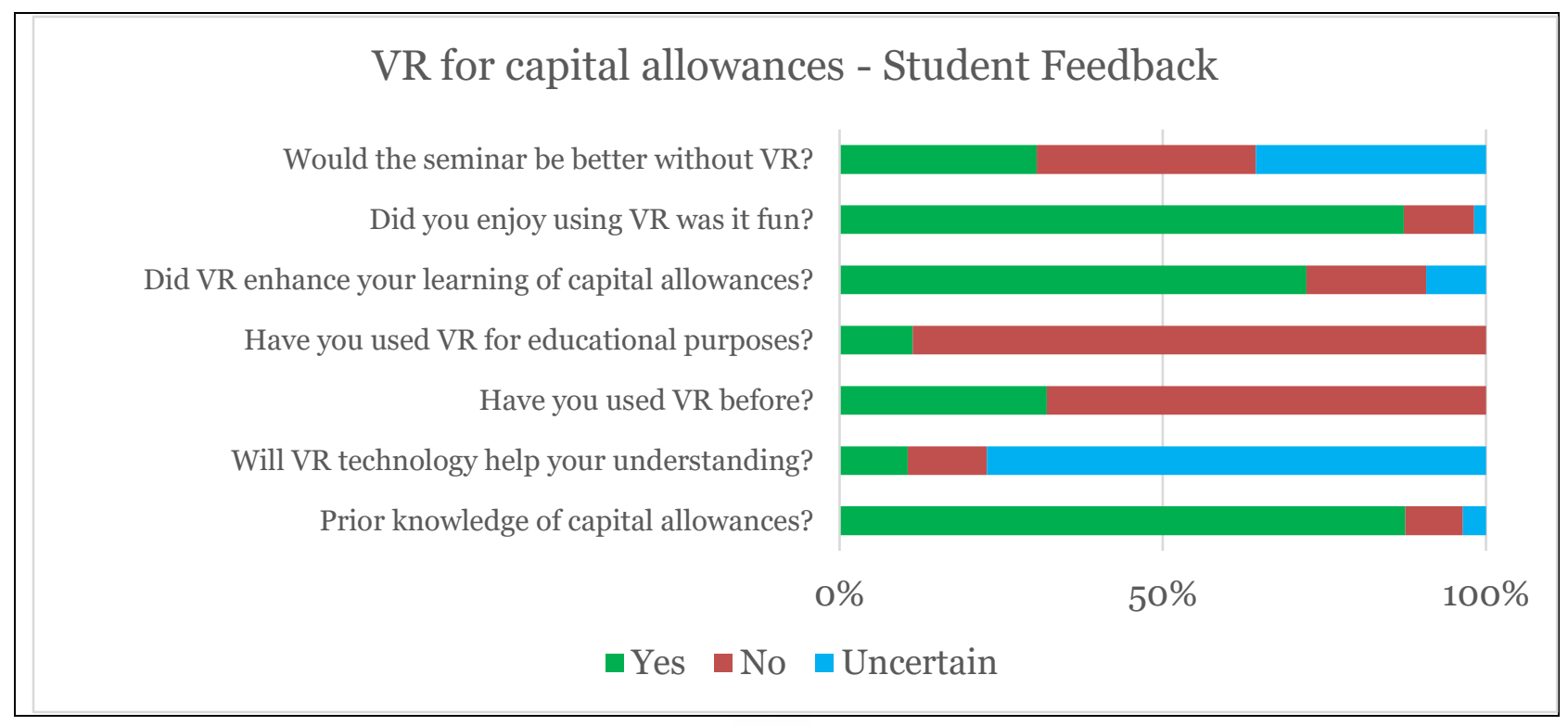

Asia Pacific Institute of Advanced Research (APIAR) DOI : 10.25275/apjcectv4i2edu6 


\section{ResultsbyQuestion \\ AppendixB}

1. Howwouldyou describeyourknowledge of capital allowances at this point(MultipleChoice)

\begin{tabular}{|c|c|c|c|c|c|c|c|c|c|c|c|c|}
\hline & \multicolumn{2}{|c|}{ Totals } & \multicolumn{2}{|c|}{ Session 1} & \multicolumn{2}{|c|}{ Session2 } & \multicolumn{2}{|c|}{ Session 3} & \multicolumn{2}{|c|}{$\operatorname{Session} 4$} & \multirow{2}{*}{\multicolumn{2}{|c|}{ Session5 }} \\
\hline & Percent & Count & Percent & count & Percent & count & Percent & count & Percent & count & & \\
\hline $\begin{array}{l}\text { Basic } \\
\text { knowledge } \\
\text { fromthe } \\
\text { lecture }\end{array}$ & & 49 & $100.00 \%$ & 6 & $100.00 \%$ & 10 & $100.00 \%$ & 10 & $84.62 \%$ & 22 & $25.00 \%$ & 1 \\
\hline $\begin{array}{l}\text { Absolutely } \\
\text { noidea }\end{array}$ & & 5 & $0.00 \%$ & $\mathrm{O}$ & $0.00 \%$ & $\mathrm{O}$ & $0.00 \%$ & $\mathrm{O}$ & $11.54 \%$ & 3 & $50.00 \%$ & 2 \\
\hline $\begin{array}{l}\text { Fairly } \\
\text { good,I } \\
\text { attended } \\
\text { thelecture } \\
\text { andhave } \\
\text { prepared } \\
\text { for today }\end{array}$ & & 2 & $0.00 \%$ & $\mathrm{O}$ & $0.00 \%$ & $\mathrm{O}$ & $0.00 \%$ & $\mathrm{O}$ & $3.85 \%$ & 1 & $25.00 \%$ & 1 \\
\hline Don'tknow & & $\mathrm{O}$ & $0.00 \%$ & $\mathbf{O}$ & $0.00 \%$ & $\mathrm{O}$ & $0.00 \%$ & $\mathrm{O}$ & $0.00 \%$ & $\mathrm{O}$ & $0.00 \%$ & 0 \\
\hline Totals & & 56 & $100 \%$ & 6 & $100 \%$ & 10 & $100 \%$ & 10 & $100 \%$ & 26 & $100 \%$ & 4 \\
\hline
\end{tabular}

2. Doyou think thatVR technology will helpyour understanding?(MultipleChoice)

\begin{tabular}{|c|c|c|c|c|c|c|c|c|c|c|c|c|}
\hline & \multicolumn{2}{|c|}{ Totals } & \multicolumn{2}{|c|}{ Session 1} & \multicolumn{2}{|c|}{ Sesrion2 } & \multicolumn{2}{|c|}{ Session3 } & \multicolumn{2}{|c|}{$\operatorname{Session} 4$} & \multirow{2}{*}{\multicolumn{2}{|c|}{$\begin{array}{l}\text { Sessian5 } \\
\text { Percent count }\end{array}$}} \\
\hline & Percent & Count & Percent & count & Percent & count & Percent & Coun & Percent & coum & & \\
\hline Yes & & 6 & $16.67 \%$ & 1 & $0.00 \%$ & 0 & $0.00 \%$ & $\mathrm{C}$ & $18.52 \%$ & ! & $0.00 \%$ & 0 \\
\hline No & & 7 & $0.00 \%$ & 0 & $0.00 \%$ & 0 & $0.00 \%$ & C & $25.93 \%$ & 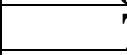 & $0.00 \%$ & $\mathbf{O}$ \\
\hline Notsure & & 25 & $66.67 \%$ & 4 & $40.00 \%$ & 4 & $40.00 \%$ & 4 & $40.74 \%$ & 1 & $50.00 \%$ & 2 \\
\hline $\begin{array}{l}\text { Havenot } \\
\text { givenitany }\end{array}$ & & 19 & $16.6 \% \%$ & 1 & $60.00 \%$ & 6 & $60.00 \%$ & 6 & $14.81 \%$ & 2 & $50.00 \%$ & 2 \\
\hline $\begin{array}{l}\text { thought } \\
\text { Totals }\end{array}$ & & $\pi$ & 00 & & & & & & & & & \\
\hline
\end{tabular}

Asia Pacific Institute of AdvancedResearch (APIAR) DOI : 10.252\%/apjcectv4i2edu6 
3. Haveyou usedVRtechnologybefore? (MultipleChoice)

\begin{tabular}{|c|c|c|c|c|c|c|c|c|c|c|c|c|}
\hline & \multicolumn{2}{|c|}{ Totals } & \multirow{2}{*}{\multicolumn{2}{|c|}{ Session 1}} & \multicolumn{2}{|c|}{ Session 2} & \multicolumn{2}{|c|}{ Session3 } & \multicolumn{2}{|c|}{$\operatorname{Session} 4$} & \multirow{2}{*}{\multicolumn{2}{|c|}{ Session 5}} \\
\hline & Percent & Count & Percent & & Percent & Count & Percent & count & Percent & count & & \\
\hline Yes & & 17 & $3333 \%$ & 2 & $40.00 \%$ & 4 & $40.00 \%$ & 4 & $25.93 \%$ & 7 & $25.00 \%$ & 1 \\
\hline No & & 36 & $6.67 \%$ & 4 & $60.00 \%$ & 6 & $60.00 \%$ & 6 & $74.0 \% \%$ & 20 & $75.00 \%$ & $\overline{3}$ \\
\hline Notsure & & 0 & $0.00 \%$ & 0 & $0.00 \%$ & 0 & $0.00 \%$ & $\mathbf{0}$ & $0.00 \%$ & 0 & $0.00 \%$ & 0 \\
\hline Totals & & 53 & $100 \%$ & 6 & $100 \%$ & 10 & $100 \%$ & 10 & $100 \%$ & 27 & $100 \%$ & 4 \\
\hline
\end{tabular}

4 Inwhat context did you use VR? (MultipleChoice)

\begin{tabular}{|c|c|c|c|c|c|c|c|c|c|c|c|c|}
\hline & Tot & & Sass & n1 & $\operatorname{Sess}$ & 0012 & Sass' & $\mathbf{n 3}$ & $\operatorname{Ses} 5$ & n 4 & Sassion 5 & \\
\hline & Percent & Count & Percent & count & Percent & count & Percent & count & Percent & count & Percent & count \\
\hline $\begin{array}{l}\text { In } \\
\text { education } \\
\text { setting }\end{array}$ & & $\mathrm{O}$ & $0.00 \%$ & $\mathrm{O}$ & $0.00 \%$ & $\mathrm{O}$ & $0.00 \%$ & $\mathrm{O}$ & $0.00 \%$ & $\mathrm{O}$ & $0.00 \%$ & $\mathrm{O}$ \\
\hline $\begin{array}{l}\text { For gaming } \\
\text { purposes }\end{array}$ & & 13 & $16.6 \% \%$ & 1 & $22.22 \%$ & 2 & $22.22 \%$ & 2 & $28.00 \%$ & 7 & $25.00 \%$ & 1 \\
\hline $\begin{array}{l}\text { For both } \\
\text { gaming } \\
\text { andin } \\
\text { education }\end{array}$ & & 6 & $16.67 \%$ & 1 & $22.22 \%$ & 2 & $22.22 \%$ & 2 & $4.00 \%$ & 1 & $0.00 \%$ & $\mathrm{O}$ \\
\hline $\begin{array}{l}\text { Neverused } \\
\text { VRbefore }\end{array}$ & & 34 & $66.67 \%$ & 4 & $55.56 \%$ & 5 & $55.56 \%$ & 5 & $68.00 \%$ & 17 & $75.00 \%$ & 3 \\
\hline Totals & & 53 & $100 \%$ & 6 & $100 \%$ & 9 & $100 \%$ & 9 & $100 \%$ & 25 & $100 \%$ & 4 \\
\hline
\end{tabular}

5. Now that you have used theVRtechnologydid you find it enhanced your learning of capital allowances? (MultipleChoice)

\begin{tabular}{|c|c|c|c|c|c|c|c|c|c|c|c|c|}
\hline & \multicolumn{2}{|c|}{ Totals } & \multicolumn{2}{|c|}{ Session 1} & \multicolumn{2}{|c|}{ Session 2} & \multirow{2}{*}{\multicolumn{2}{|c|}{ Session3 }} & \multirow{2}{*}{\multicolumn{2}{|c|}{ Session 4}} & \multirow{2}{*}{\multicolumn{2}{|c|}{ Session 5}} \\
\hline & Percent & Count & Percent & count & Percent & count & & count & & count & & \\
\hline Yes & & 39 & $85.71 \%$ & 6 & $90.00 \%$ & 9 & $90.00 \%$ & 9 & $56.52 \%$ & 13 & $50.00 \%$ & 2 \\
\hline No & & 10 & $0.00 \%$ & $\mathbf{O}$ & $10.00 \%$ & 1 & $10.00 \%$ & 1 & $34.78 \%$ & 8 & $0.00 \%$ & $\mathbf{O}$ \\
\hline Notsure & & 5 & $14.29 \%$ & 1 & $0.00 \%$ & $\mathbf{O}$ & $0.00 \%$ & 0 & $8.70 \%$ & 2 & $50.00 \%$ & 2 \\
\hline Totals & & 54 & $100 \%$ & 7 & $100 \%$ & 10 & $100 \%$ & 10 & $100 \%$ & 23 & $100 \%$ & 4 \\
\hline
\end{tabular}

Asia Pacific Institute of AdvancedResearch (APIAR) DOI : 10.252/5/apjcectv4i2edu6 


\title{
Appendix C
}

\author{
Student Feedback
}

- Enjoy, exciting, work together with other students to find capital (group 4)

- Enjoyable, got to see how different equipment are costed in various rooms (group 4)

- Using this technology is really fun and we did have a marvelous experience (group 4)

- It may stimulate students interest (group 4)

- Using virtual reality is an important tool when using it for learning purposes. It allows you to use imagery when learning which in my opinion is much more memorable than a piece of notes. It allows you to experience what your actually studying. Really enjoyed it. I would like to see this implemented into management accounting and financial accounting. Overall, I think VR is a great experience for earning and should be used much more (group 4)

- Very quick and detailed. Helpful with understanding, maybe a need to sort out the sickness and dizziness which I experienced. Would be good if the app was usable on iphones. Good experience, helps with confidence in the real world (group 4)

- It was very fun to use and interesting, don't know how it would help to learn an accounting course (group 4)

- Not sure if it enhances our learning in any way. Maybe good for other subjects (not accounting or finance (group 5)

- I think study with VR technology is very fun. It increase my learning initiative. I wish I can have another seminar with VR technology (group 5)

- Very dizzy - not sure if the info recorded is complete, have fun, have different sensation from common study (group 5)

- It is very interesting but made me feel a little dizzy. The vision is so vivid (group 4)

- Dizzy but useful and clear. I can look at the whole view of inventory (group 4)

- Pros - I think VR technology makes class more interesting and students are more willing to get involved with class. Using VR technology for capital allowances helps student to understand which capital we should claim. Cons, it makes me dizzy (group 4)

- Benefit: fun, interest, pay more attention in seminar, disadvantages, may not be efficient (group 4)

- Makes the class more interest (group 4)

- It is amazing enhance my learning ability (group 4)

- So much fun (:) (group 4)

- Good idea to use VR (group 4)

- Fun, makes it more real life and practical, might take up too much time in lectures ie. We have not actually learnt anything today. It was fun but that's not going to help me pass my exam (group 4)

- Liked it and would prefer them in seminar classes (group 4)

- It was a great learning tool as we got to visualize the assets instead of just going through lists. Moreover, it was great as it incorporated team work. I enjoyed it (group 4)

- Decent to see what actually gets valued in real world @(group 4)

- Should include info in the VR to explain allowances (group 4)

- I think it is very fun to use VR technology as an instrument to help us learn the module content better. I like that (group 4)

- Excellent idea as it relieve us from boring study and enrich our experience. Thank you for your thoughts and it would be really beneficial to us. Really fun and enjoy (group 4) 
- Really funny, but not so efficient. Straight forward but in real life there won't be this kind of straight forward way when we calculate taxes (group 4)

- While it exposes us to the "real world" it is still not much help when it comes to theory and exams (group 4)

- All we did was look round a room didn't actually learn anything, knew in terms of capital allowances was useful in terms of real world experience (group 4)

- Not really good for long term as it gives you a headache not useful enough (group 4)

- Great new learning technique, not sure it was relevant for tax purposes, would like to see more of it as its different/fun (group 4)

- Difficulty with cardboard - button sticks otherwise worked well (group 4)

- Its good new way to learn things (group 4)

- Useful to have as a teaching option, slightly more time consuming than a normal seminar (group 2)

- I enjoyed using the VR set, although the frame rate on my phone was a little slow to not make me not feel sick. Good use of situation and real life practicals (group 2)

- Good despite queezy-ness interactive and interesting, useful to see real life situation (group 2)

- Overall, the VR session is fun but using it for a long period of time may feel dizzy and feel a bit unreal. I would love to have VR session like quarter of the seminar session and 30 minutes for taught session that would help a lot in enjoying learning through VR (group 2)

- VR is quite interesting undoubtedly and it is so special way to get to know the knowledge point of each specific area. As a learning tool, VR can really enhance students interest in learning. I like it soooomuch, and enjoyed it very much. Thank you for provding me such an unforgettable experience (group 2)

- Generally good and gave helpful examples of real world, but was quite time consuming and I wouldn't want to use it all the time (group 2)

- I think that the use of VR was a good learning tool as I used it for the first time. However, I think that it will not benefit me for my exam. I would prefer to go through questions like we did in the lecture (group 2)

- More in modules like in taxation as it involves a lot more practical knowledge and helps with revision (group 2)

- That's fun, I enjoy it. This learning tool would be interesting (group 2)

- Was fun to have a new way of learning, makes it easier to put stuff up. A good way of teaching going forward, should be compatible with iphones (group 2)

- Good way of seeing what it was actually like in this type of activity/question (group 2)

- Sick, dizzy, but also fun and enjoyable, ginger biscuits may help or better headsets (group 2)

- I enjoyed using VR technology and fell should be more in the classroom (group 3)

- Good idea but head hurts (group 3)

- It was interesting seeing how one would identify capital allowances but I have not been able to clarify what are allowances from this. I found it dizzy using the VR (group 3)

- Use of VR was something different from the usual seminar session. Even though it was fun and interesting I believe that it took a bit longer to understand and use. I believe the use of VR is limited for the course/subject, time consuming and making everyone a little dizzy. Other than that it was something that help engage students in a fun way. Maybe if there are more supplies for everyone, then I think it would be an interesting tool to look in the future (group 3)

- Enjoyed using VR. Didn't feel I learnt anything (group 3) 
- It is very cool for VR using in the class of accounting. I hope the tech of VR can using in more fields like finance, business subject or module. I suggest Swansea uni can explore more tech such as VR for use in the class. Thank you! (group 3)

- I can see more classrooms or technology rooms or other rooms I have never been before. It is fun to use VR while learning (group 3)

- It was fun but not sure if it was useful (group 3)

- Was good, but maybe would be better as a longer activity, helped solidify capital allowances (group 3)

- It was good because it is something different, good occasionally in seminars but traditional seminars are also useful (group 3)

- I think it was good and better than a seminar without it. Could be used for benefits in kind looking at what's allowable and what's not such as products entertaining customers etc. (group 3)

- Made you think more about what you're actually doing, makes it more transferrable to a job. Engaging (group 5)

- Great way to get everyone involved, makes it more exciting. Helps to understand things better as you can see it. Great seminar (group 5)

- Interesting experience and keep engaged with the subject matter, perhaps fewer rooms as maybe not so many are needed, not sure it enhanced my learning of the subject matter however it is a good variation from normal sessions (group 5)

- It was fun but due to personal issue, I wasn't really enjoying it. However, it can be useful in the education field - using VR. For a more realistic vision to students (group 5)

- Great idea (group 1)

- Is interesting, more interactive learning, could be very useful if we are taught at the same time rather than just looking around as didn't learn much. Did get a slight headache (group 1)

- It is very interesting, It is a good way to learn taxation (group 1)

- Was interesting, but think it needs to be used on smaller groups and with more area around, new way of engaging with students once course are run more frequently with different lecturers and seminars. Should be used more often (group 1)

Fun interesting learning, maybe adds distractions to learning, not really useful for accounting purposes, fun mind (group 1) 